\title{
Editorial
}

\section{THE WORDS OF PROF. DR. DOMINGO M. BRAILE}

$\mathrm{S}$ ince we took on the responsibility as Editors of the Brazilian Journal of Cardiovascular Surgery (BJCVJ) we had ambitious goals, to improve the already excellent quality of our journal and to increase its coverage and importance. In spite of some perfectly understandable obstacles, we have had several victories, including the publication of the electronic version in Scielo in both English and Portuguese and a greater recognition in the national and international scientific communities. We are now receiving manuscripts from other countries, which is proof of this. This edition includes an original article from Argentinean authors (Page 39) and a Case report written by Italian authors (Page 88).

The challenge now is to bring together the quantity and quality. We need to have enough works available to increase the number of articles per edition so that our journal is comparable to the best publications of the world. Thus, we are grateful for the editorial "Victories, but there are still great challenges ahead" written by our associate editor Dr. Walter Gomes and published in this edition. We recommend that you carefully read his words.

We stress that it is essential that Brazilian cardiovascular surgeons and allied professionals, who produce extremely useful and dedicated work, write down their experiences and the techniques they develop and send them to us. Letters are very important too, as they create stimulating exchanges of knowledge.

We know that writing an article is not always easy. Because of this, over almost three years now, we have tried to publish articles to guide authors, aiming at diminishing doubts and to help authors overcome difficulties. In this edition, a special article written by our staff, by the editorial assistant Rosangela Monteiro and by Ricardo Brandau the executive editor, highlights the importance of using the correct descriptors and shows how to find them on the Internet. We stress that members of the editorial staff of the BJCVS are available to help anybody who has difficulties in writing articles. The site of the CTSNet has a link in English (http:// www.ctsnet.org/doc/9093) which gives valuable information on how to write a work.

We would like, once again, to ask authors whose works were selected for the $32^{\text {nd }}$ Congress of the Brazilian Society of the Cardiovascular Surgery from $28^{\text {th }}$ to $30^{\text {th }}$ April, in Vitória, Espírito Santo, to give a copy of their work to representatives of the BJCVS present at the event. We know that the works are of a high standard and will help us to enrich our Journal. We also remind you that there was a decision by the BSCVS directorate that no work should be presented if it has not been previously delivered in its final form before the presentation (preferably in an electronic format on $\mathrm{CD}$ or diskette). Unfortunately, we were not accepted in Medline yet, but we are continuing to work hard to adapt to the demands of the selection committee and soon we will re-apply to be indexed. In May I will be going to the United States, when I will have the opportunity to speak with the Selection Committee of Medline in Washington to present our request personally, presenting the BJCVS in its paper and electronic formats. For this, we require that the standard of 
the journal remains high, both aesthetically and in content. We will be grateful for and will carefully assess any suggestion to improve the journal.

We have some good news to share with our colleagues. CNPq, due to the efforts of our President Alexandre Brick and colleague Ricardo Lima, approved an extra editorial grant to the tune of 40 thousand Reals. This budget must be utilized exclusively to improve the publication on Internet. With this sum, we intend to modernize our equipment and to facilitate the flow of the submission and review of the articles. For this, we will acquire a service management computer program, which will automate the flow of works, speeding up and simplifying the work to authors and reviewers. Currently, we are searching for the best system to fulfill our necessities and we intend to implant the new system by the middle of this year, at the latest. Everyone will gain with the speed that the new software is going to provide.

This assistance of CNPq, given to several Brazilian publications, leads to discussions about the access to journals. The majority of high level international journals charge to be read on the Internet. This makes access for researchers difficult and obliges institutions, such as colleges and governmental organs, to allocate much money to make this information available to their public. This model is being put in check by "PloS" (www.plos.org), which has already been mentioned by us in an editorial in the 18.4 edition of our journal, where readers are not charged but authors need to pay.

The Folha de São Paulo newspaper, in an editorial published on 27 January of this year, talked about the question scientific publication, empathizing the significance of peer-reviewing and mentioning the case of "PloS", indicating it as being an initiative which deserves to be watched as it makes the vast knowledge of discoveries and advances of Science available. The BJCVS will continue to offer free access as it is indexed to Scielo, but we will always be open to discussion about the theme, which is of interest of all those who are really worried about the publication of scientific knowledge.

We would like to thank yet again the help given by the directorate of the BSCVS, which has understood the importance of the journal and has always tried to help by fulfilling its necessities. We also thank all the advertisers for their trust in us. We are especially thankful for the presence of the Hospital Português of Recife and the return of Saint Jude to our pages.

We always believe in the capacity of Brazil and of the Brazilian, which with work, determination and creativity know how to overcome difficulties over more than 500 years of history. To invest in science is a good business, despite of the results are not normally detected over the short time. The more that Brazil puts value in scientific research, the more will be the possibility of improving both economic and socially and to be compared to the more developed nations.

Receive my warmest wishes,

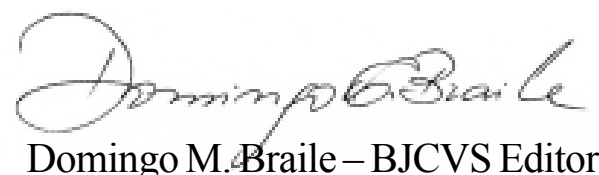

